\title{
Neuroimaging in cluster headache and other trigeminal autonomic cephalalgias
}

\author{
Elisa Iacovelli • Gianluca Coppola • \\ Emanuele Tinelli • Francesco Pierelli • \\ Federico Bianco
}

Received: 31 July 2011/Accepted: 4 November 2011/Published online: 25 November 2011

(C) The Author(s) 2011. This article is published with open access at Springerlink.com

\begin{abstract}
The central nervous system mechanisms involved in trigeminal autonomic cephalalgias, a group of primary headaches characterized by strictly unilateral head pain that occurs in association with ipsilateral craniofacial autonomic features, are still not comprehensively understood. However, functional imaging methods have revolutionized our understanding of mechanisms involved in these primary headache syndromes. The present review provides a brief overview of the major modern functional neuroimaging techniques used to examine brain structure, biochemistry, metabolic state, and functional capacity. The available functional neuroimaging data in cluster headache and other TACs will thus be summarized. Although the precise brain structures responsible for these primary headache syndromes still remain to be determined, neuroimaging data suggest a major role for posterior hypothalamus activation in initiating and maintaining attacks. Furthermore, pathophysiological involvement of the pain neuromatrix and of the central descending opiatergic pain
\end{abstract}

E. Iacovelli $(\bowtie) \cdot$ E. Tinelli $\cdot$ F. Bianco

Neurology Section, Department of Medico-Surgical Sciences and Biotechnologies, "Sapienza" University of Rome,

Viale dell'Università 30, 00185 Rome, Italy

e-mail: elisa_iaco@yahoo.it

G. Coppola

Department of Neurophysiology of Vision and Neurophthalmology, G.B. Bietti Eye Foundation-IRCCS, Rome, Italy

F. Pierelli

Department of Medico-Surgical Sciences and Biotechnologies,

"Sapienza" University of Rome, Polo Pontino, Latina, Italy

F. Pierelli

IRCCS-Neuromed, Pozzilli (IS), Italy control system was observed. Given the rapid advances in functional and structural neuroimaging methodologies, it can be expected that these non-invasive techniques will continue to improve our understanding into the nature of the brain dysfunction in cluster headache and other trigeminal autonomic cephalalgias.

Keywords Trigeminal autonomic cephalalgias .

Hypothalamus · Pain neuromatrix · Single photon emission computed tomography - Positron emission tomography . Magnetic resonance spectroscopy · Functional MRI . Voxel-based morphometry

\section{Introduction}

Trigeminal autonomic cephalalgias (TACs), such as cluster headache $(\mathrm{CH})$, paroxysmal hemicrania $(\mathrm{PH})$ and shortlasting unilateral neuralgiform headache attacks with conjunctival injection and tearing (SUNCT) are a group of primary headaches which share the activation of the trigeminal nerve in mediating pain and of the parasympathetic component of the seventh cranial nerve in producing the local autonomic symptoms [1]. However, the CNS mechanisms involved in these primary headaches are still not comprehensively understood.

Modern methods of functional neuroimaging have revolutionized our way of exploring brain function, and their application in the study of TACs has provided great advances in the understanding of their pathophysiological facets.

Here, we will provide first a brief overview of the neuroimaging techniques used to study brain function in TACs. Thereafter, we will review the knowledge acquired with these functional neuroimaging methods on the pathophysiology of primary headaches. 


\section{Neuroimaging techniques}

While early studies in trigeminal autonomic headache were done exclusively with positron emission tomography (PET), the development of new imaging techniques as well as the increase in image resolution have led to an expansion in the applications of magnetic resonance (MR) based imaging methods in headache. Both PET and MR-based imaging methods have now been widely used in trigeminal autonomic headache research. As well as these imaging methods that enable us to investigate the function of the brain during headache attacks, structural and morphometric methods, such as voxel-based morphometry, have also become available. In contrast to conventional methods, voxel-based morphometry allows the comparison of the local concentration of gray matter between groups of subjects and the correlation of whole-brain gray matter density with clinical variables of the disease.

Single photon emission computed tomography (SPECT)

First studies in headache research have applied SPECT, a procedure based on nuclear medicine imaging techniques. SPECT can be used to define a patient's pathologic status when neurologic or psychiatric symptoms cannot be explained by structural neuroimaging findings [2]. Molecules labeled with a radioactive isotope are administered by IV injection. A positron-sensitive detector allows the detection of photon emissions. SPECT isotopes are chosen on the basis of their chemical, biologic, and nuclear properties [3]. The main characteristics include: a half-life long enough to allow tracer preparation, injection, and uptake and image acquisition and short enough not to deliver an unnecessary dose to the patient; gamma emission energy sufficiently high to escape from the patient, but sufficiently low to facilitate collimation and detection and favorable dosimetry to limit patient exposure [3]. The tracer and isotopes commonly used in brain SPECT are xenon-133 $\left({ }^{133} \mathrm{Xe}\right)$, iodine-123 isopropyliodoamphetamine $\left({ }^{123}\right.$ I-IMP), more recently replaced by technetium-Tc99mlabeled hexamethylpropyleneamine oxime (Tc99mHMPAO) and Tc99m-ethyl cysteinate dimer (ECD). The brain perfusion imaging agents $99 \mathrm{mTc}-\mathrm{HMPAO}$ and $99 \mathrm{mTc}-\mathrm{ECD}$ are sensitive indicators of regional cerebral blood flow $(\mathrm{rCBF})$ changes and can detect a reduction in blood flow [2].

\section{Positron emission tomography}

In headache research many studies have applied PET. PET is a nuclear medicine imaging technique that permits to acquire images of physiologic function by studying cerebral blood flow as an indirect marker of neuronal activity. The scan uses a gamma-ray emitting radio-isotope bound to a biologically active molecule. The radiotracers principally used are 2-deoxy-2-[18F] fluoro-D-glucose (18FDG) $[4,5],{ }^{15} \mathrm{O}$ labeled water $\left(\mathrm{H}_{2}^{15} \mathrm{O}\right)[6]$, or radioactively labeled ligands that bind to specific receptors [7, 8]. After seconds or few minutes following the injection or inhalation of the radiopharmaceutical, the radio-isotope decays emitting a positron, which moves a short distance before annihilating with an electron. The annihilation produces a couple of photons that are detected with a gamma camera. In modern scanners, three-dimensional images of tracer concentration within the body are then constructed by computer analysis, accomplished with the aid of a CT $\mathrm{X}$-ray scan, performed at the same time. Radiopharmaceuticals most commonly used, such as $18 \mathrm{FDG}$ and $\mathrm{H}_{2}^{15} \mathrm{O}$, allow imaging of tissue metabolic activity, in terms of regional glucose uptake or blood flow changes, respectively. Imaging of the tissue concentration of other types of molecules of interest can be obtained by using different tracers.

\section{Magnetic resonance spectroscopy}

Magnetic resonance spectroscopy (MRS) is based on the principle that the resonance frequency of a nucleus depends on its chemical environment, produces a small, but perceptible, change in the resonance frequency of that nucleus. This nuclear behavior is termed "chemical shift" and is caused by the magnetic fields generated by circulating electrons surrounding the nuclei, interacting with the main magnetic field. Protons $\left({ }^{1} \mathrm{H}\right)$ have been traditionally used for MRS because of their high natural abundance in organic structures and high nuclear magnetic sensitivity compared with any other magnetic nuclei [9]. Moreover, diagnostically resolvable hydrogen MR spectra may be obtained with clinical instruments (1.5 $\mathrm{T}$ or greater) and routine coils. MR spectroscopy allows mapping the distribution of metabolite concentrations within small volumes of cerebral tissue, termed volume of interest (VOI) [10]. Using long echo-times (TEs), the signal from most metabolites in the brain is lost except for choline (Cho), creatine (Cr), $N$-acetyl aspartate (NAA), and lactate. NAA is accepted as a marker of neuronal density and viability. Cho is a metabolic marker of membrane density and integrity. The peak for $\mathrm{Cr}$ is a marker of energy metabolism. Lactate appears under conditions where the aerobic oxidation mechanism fails and anaerobic glycolysis takes over. Lipids reflect necrotic processes [11]. Moreover, other metabolites (e.g., myoinositol, glutamate, glutamine, and glycine) can be identified by using short TEs [12] 


\section{Functional MRI}

Functional MRI was used to generate the first functional magnetic resonance maps of human task activation. In 1990, Ogawa et al. [13] reported that MRI was sensitive enough to show "blood oxygenation level-dependent" (BOLD) signal changes in vivo. Since it was known that changes in neuronal activity were accompanied by local changes in brain oxygen content [14], it became evident that a technique based on the BOLD effect could potentially be used to investigate neuronal activation through changes induced in tissue oxygenation. The signal changes in BOLD fMRI are determined by the paramagnetic properties of deoxyhemoglobin (deoxy-Hb) [15]. According to the BOLD signal theory, these changes are determined by a marked increase in regional blood flow. Because blood oxygenation levels change rapidly following the activity of neurons in a brain region, fMRI allows researchers to localize brain activity on a second-by-second basis, and within millimeters of its origin. In addition to the BOLD effect, other mechanisms are supposed to contribute to the endogenous MR contrast. It is well known that inflow effects make some contribution to the functional signal change [16].

\section{Voxel-based morphometry}

Voxel-based morphometry (VBM) permits to identify volume differences in brain anatomy between groups of subjects, performing statistical tests across all voxels in the image [17]. The procedure involves the acquisition of T1weighted volumetric MRI scans that are registered onto the same template image so that they are all in the same space, to perform statistical analyses across multiple MRI scans from different individuals. This process is known as spatial normalization [18]. The spatially normalized images are next segmented into gray matter (GM), white matter (WM) and cerebrospinal fluid (CSF). Although both gray and white matter volumes can be assessed using VBM, the majority of VBM studies concentrate on gray matter [18]. The images, after the normalization and segmentation, are smoothed and processed to perform a parametric statistical analysis [17]. All voxels that refute the null hypothesis and show statistical significance generate statistical maps that are often shown as color maps with the scale representing the $t$ statistic [18]. However, in more recent studies, the segmentation of images into GM, WM and CSF is first performed and then GM maps are applied a high-dimensional DARTEL normalization modulating for nonlinear effects [19, 20].

In the following section, we will summarize the results of functional imaging studies on trigeminal autonomic headache syndromes, showing how functional neuroimaging has advanced our understanding of trigeminal autonomic headache pathophysiology (Tables 1, 2).

\section{Neuroimaging in trigeminal autonomic cephalalgias}

The group includes cluster headache $(\mathrm{CH})$, paroxysmal hemicrania $(\mathrm{PH})$, and short-lasting unilateral neuralgiform headache attacks with conjunctival injection and tearing (SUNCT). These syndromes differ in attack duration and frequency and present different responses to therapy [21].

\section{Cluster headache}

$\mathrm{CH}$ is the most frequent syndrome. The pain is located mainly around the orbital and temporal regions, though any part of the head can be affected. The headache usually lasts 45-90 min but can range between $15 \mathrm{~min}$ and $3 \mathrm{~h}$. Typically, this syndrome is characterized by a striking circannual and circadian pattern. There is a clear male preponderance.

Usually headache attacks cluster in time, lasting for 7 days to a year separated by remission periods lasting for months or years (80-90\% of patients). Sometimes attacks recur for more than 1 year without remission periods, then becoming chronic (10-20\% of patients) [21, 22].

Early neuroimaging studies in cluster headache evaluated cerebral blood flow, using mainly SPECT. This semiquantitative method has not provided univocal results, since some studies reported an increase, some a decrease and others no differences in cortical blood flow, possibly because of methodological dissimilarities [23-27]. Di Piero et al. [28], aiming to investigate brain response to pain in 7 cluster headache patients out of the bout compared to 12 healthy controls, recorded Xe-133 SPECT during experimentally induced pain by means of a cold water pressor test. They demonstrated less cerebral blood flow modifications in contralateral primary sensorimotor and thalamic regions compared to healthy subjects only when the CPT was performed on the $\mathrm{CH}$ side. This led the authors to suggest the possible involvement of central tonic pain mechanisms in the pathogenesis of cluster headache. Hsieh and coworkers performed $\left[{ }^{15} \mathrm{O}\right]$ butanol PET in 7 patients affected by episodic $\mathrm{CH}$ (4 in and 3 out of the bout) during nitroglycerine-induced pain. PET scan showed a significantly increased $\mathrm{rCBF}$ in the right caudal and rostrocaudal anterior cingulate cortex (ACC), temporopolar region, supplementary motor area, bilaterally in the primary motor and premotor areas, opercular region, insula/putamen, and lateral inferior frontal cortex. Moreover, a reduction in rCBF bilaterally in the posterior-parietal cortex, occipitotemporal region and prefrontal cortex was observed [29]. May and colleagues, scanning nine chronic $\mathrm{CH}$ patients 
Table 1 All neuroimaging findings in cluster headache and other trigeminal-autonomic cephalalgias

\begin{tabular}{|c|c|c|c|c|}
\hline Reference & $\begin{array}{l}\text { No. of subjects } \\
\text { and diagnosis }\end{array}$ & Timing of the scan & $\begin{array}{l}\text { Neuroimaging } \\
\text { techniques }\end{array}$ & Main results \\
\hline $\begin{array}{l}\text { Norris et al. } \\
{[23]}\end{array}$ & 1 episodic $\mathrm{CH}$ & During the attack & SPECT & No differences in mean $\mathrm{CBF}$ \\
\hline $\begin{array}{l}\text { Sakai et al. } \\
{[24]}\end{array}$ & 9 episodic $\mathrm{CH}$ & & SPECT & Increased CBF \\
\hline $\begin{array}{l}\text { Henry et al. } \\
{[25]}\end{array}$ & 3 episodic $\mathrm{CH}$ & $\begin{array}{l}\text { Inside a bout during an } \\
\text { attack }\end{array}$ & SPECT & No differences in mean $\mathrm{CBF}$ \\
\hline $\begin{array}{l}\text { Nelson et al. } \\
\text { [26] }\end{array}$ & 26 episodic $\mathrm{CH}$ & $\begin{array}{l}4 \text { during the attack. } \\
7 \text { after nitroglycerine, } \\
\text { alcohol, histamine or } \\
\text { oxygen }\end{array}$ & SPECT & $\begin{array}{l}\text { Patients showed a variable pattern of } \\
\text { increased or decreased mean CBF }\end{array}$ \\
\hline $\begin{array}{l}\text { Krabbe et al. } \\
\text { [27] }\end{array}$ & 18 episodic $\mathrm{CH}$ & $\begin{array}{l}18 \text { outside the attacks } \\
8 \text { during the attack }\end{array}$ & SPECT & No differences in mean $\mathrm{CBF}$ \\
\hline $\begin{array}{l}\text { Di Piero et al. } \\
\text { [28] }\end{array}$ & 7 episodic $\mathrm{CH}$ & Outside of a bout & SPECT & $\begin{array}{l}\text { CBF lower in contralateral primary } \\
\text { sensorimotor and thalamic regions } \\
\text { compared to healthy subjects }\end{array}$ \\
\hline $\begin{array}{l}\text { Hsieh et al. } \\
\text { [29] }\end{array}$ & 7 episodic $\mathrm{CH}$ & $\begin{array}{l}4 \text { during the bout } \\
3 \text { out of the bout } \\
\text { (nitroglycerine-induced } \\
\text { attacks) }\end{array}$ & PET & $\begin{array}{l}\text { Increased } \mathrm{rCBF} \text { in the right caudal and } \\
\text { rostrocaudal ACC, temporo-polar } \\
\text { region, supplementary motor area, } \\
\text { bilaterally in the primary motor area, } \\
\text { premotor areas, opercular region, insula/ } \\
\text { putamen, and lateral inferior frontal } \\
\text { cortex } \\
\text { rCBF lower in the bilateral posterior } \\
\text { parietal cortex, occipito-temporal region } \\
\text { and prefrontal cortex }\end{array}$ \\
\hline $\begin{array}{l}\text { May et al. } \\
{[30]}\end{array}$ & 9 chronic $\mathrm{CH}$ & $\begin{array}{l}\text { During a bout } \\
\text { (nitroglycerine-induced } \\
\text { attacks) }\end{array}$ & PET & $\begin{array}{l}\text { Inferior hypothalamic grey matter } \\
\text { activation ipsilateral to the headache } \\
\text { side. Increased rCBF in the contralateral } \\
\text { ventroposterior thalamus, the anterior } \\
\text { cingulate cortex, and in the insulae } \\
\text { bilaterally }\end{array}$ \\
\hline $\begin{array}{l}\text { Sprenger } \\
\text { et al. [31] }\end{array}$ & 1 chronic $\mathrm{CH}$ & $\begin{array}{l}\text { During a bout (spontaneous } \\
\text { attacks) }\end{array}$ & PET & $\begin{array}{l}\text { Inferior hypothalamic grey matter } \\
\text { activation. Increased rCBF in the medial } \\
\text { thalamus and contralateral perigenual } \\
\text { ACC }\end{array}$ \\
\hline $\begin{array}{l}\text { May et al. } \\
\text { [32] }\end{array}$ & 17 episodic $\mathrm{CH}$ & $\begin{array}{l}9 \text { during a bout } \\
8 \text { outside of a bout } \\
\text { (nitroglycerine-induced } \\
\text { attacks) } \\
1 \text { spontaneous attack }\end{array}$ & $\begin{array}{l}\text { PET } \\
\text { MRA }\end{array}$ & $\begin{array}{l}\text { Activation ACC bilaterally, ipsilateral } \\
\text { posterior thalamus, ipsilateral basal } \\
\text { ganglia, ipsilateral inferior posterior } \\
\text { hypothalamus, frontal lobes, insulae } \\
\text { bilaterally, contralateral inferior frontal } \\
\text { cortex. } \\
\text { Increased CBF in the internal carotid } \\
\text { artery ipsilateral to the headache side, } \\
\text { both in CH patients and in } \\
\text { experimentally induced pain }\end{array}$ \\
\hline $\begin{array}{l}\text { Sprenger } \\
\text { et al. [4] }\end{array}$ & $\begin{array}{l}11 \text { episodic } \mathrm{CH} \\
\text { patients }\end{array}$ & In- and outside of a bout & FDG-PET & $\begin{array}{l}\text { Increased metabolism in the perigenual } \\
\text { ACC, posterior cingulate cortex, the } \\
\text { orbitofrontal cortex including the } \\
\text { nucleus accumbens, ventrolateral } \\
\text { prefrontal cortex, DLPFC and temporal } \\
\text { cortex, cerebellopontine area. } \\
\text { Hypometabolism in the perigenual } \\
\text { ACC, prefrontal and orbitofrontal cortex }\end{array}$ \\
\hline $\begin{array}{l}\text { Lodi et al. } \\
\text { [34] }\end{array}$ & $\begin{array}{l}18 \text { episodic } \mathrm{CH} \\
8 \text { chronic } \mathrm{CH}\end{array}$ & $\begin{array}{l}10 \text { in- and } 8 \text { outside } \\
\text { of a bout }\end{array}$ & ${ }^{1} \mathrm{H}-\mathrm{MRS}$ & $\begin{array}{l}\text { Reduction of NAA in the hypothalamus } \\
\text { of all the patient groups }\end{array}$ \\
\hline
\end{tabular}


Table 1 continued

\begin{tabular}{|c|c|c|c|c|}
\hline Reference & $\begin{array}{l}\text { No. of subjects } \\
\text { and diagnosis }\end{array}$ & Timing of the scan & $\begin{array}{l}\text { Neuroimaging } \\
\text { techniques }\end{array}$ & Main results \\
\hline Wang et al. [35] & 47 episodic $\mathrm{CH}$ & In- and outside of a bout & ${ }^{1} \mathrm{H}-\mathrm{MRS}$ & $\begin{array}{l}\text { Reduction of NAA and Cho/Cr metabolite } \\
\text { ratio in the hypothalamus }\end{array}$ \\
\hline May et al. [36] & 25 episodic $\mathrm{CH}$ & In- and outside of a bout & VBM & $\begin{array}{l}\text { Increase in bilateral hypothalamic gray } \\
\text { matter volume }\end{array}$ \\
\hline Sprenger et al. [6] & $\begin{array}{l}6 \text { episodic } \mathrm{CH} \\
1 \text { chronic } \mathrm{CH}\end{array}$ & $\begin{array}{l}\text { During the bout, but out of } \\
\text { an acute attack }\end{array}$ & $\begin{array}{l}\text { PET with the opioidergic } \\
\text { ligand } \\
{[11 \mathrm{C}] \text { diprenorphine }}\end{array}$ & $\begin{array}{l}\text { Decreased tracer binding in the pineal } \\
\text { gland }\end{array}$ \\
\hline Morelli et al. [39] & 4 episodic $\mathrm{CH}$ & $\begin{array}{l}\text { Inside the bout during an } \\
\text { acute attack }\end{array}$ & fMRI & $\begin{array}{l}\text { Activation of hypothalamus, pre-frontal } \\
\text { cortex, anterior cingulate cortex, } \\
\text { contralateral thalamus, ipsilateral basal } \\
\text { ganglia and the insula and the cerebellar } \\
\text { hemispheres bilaterally }\end{array}$ \\
\hline $\begin{array}{l}\text { Matharu et al. } \\
\text { [43] }\end{array}$ & $7 \mathrm{PH}$ & $\begin{array}{l}\text { During acute attack-off } \\
\text { indomethacin or pain- } \\
\text { free-off indomethacin or } \\
\text { pain-free due to } \\
\text { indomethacin } \\
\text { administration }\end{array}$ & $\mathrm{H}_{2}^{15} \mathrm{O}$ PET & $\begin{array}{l}\text { Activation in the contralateral posterior } \\
\text { hypothalamus, contralateral ventral } \\
\text { midbrain, ipsilateral lentiform nucleus, } \\
\text { anterior and posterior cingulate cortices, } \\
\text { bilateral insulae, bilateral frontal } \\
\text { cortices, contralateral temporal cortex, } \\
\text { contralateral postcentral gyrus, } \\
\text { precuneus, and contralateral cerebellum. } \\
\text { Indomethacin administration turned off } \\
\text { the persistent metabolic activation } \\
\text { observed during acute attack-off } \\
\text { indomethacin }\end{array}$ \\
\hline May et al. [45] & 1 SUNCT & $\begin{array}{l}\text { During } 6 \text { consecutive } \\
\text { attacks }\end{array}$ & fMRI & $\begin{array}{l}\text { Activation in the ipsilateral inferior } \\
\text { posterior hypothalamic gray matter }\end{array}$ \\
\hline Cohen et al. [47] & 2 SUNCT & During the attacks & fMRI & $\begin{array}{l}\text { Activation in the inferior posterior } \\
\text { hypothalamic gray matter bilaterally }\end{array}$ \\
\hline $\begin{array}{l}\text { Sprenger et al. } \\
\text { [46] }\end{array}$ & $\begin{array}{l}1 \text { probable } \\
\text { SUNCT }\end{array}$ & During the attack & fMRI & $\begin{array}{l}\text { Activation in the ipsilateral hypothalamic } \\
\text { gray matter, cingulate cortex, insula, } \\
\text { temporal cortex, and frontal cortex }\end{array}$ \\
\hline $\begin{array}{l}\text { Sprenger et al. } \\
\text { [48] }\end{array}$ & 1 SUNCT & $\begin{array}{l}\text { During attacks induced } \\
\text { touching the upper with } \\
\text { the lower lip }\end{array}$ & fMRI & $\begin{array}{l}\text { Activation in the hypothalamic gray } \\
\text { matter bilaterally }\end{array}$ \\
\hline
\end{tabular}

with $\mathrm{H}_{2}^{15} \mathrm{O}$ PET during nitroglycerine-induced attacks, were the first to clearly demonstrate inferior hypothalamic gray matter activation ipsilateral to the headache side. Moreover, they observed an increased $\mathrm{rCBF}$ in the contralateral ventroposterior thalamus, the anterior cingulate cortex, and in the insulae bilaterally as well [30]. Later, other authors confirmed these data in a spontaneous headache attack of a chronic $\mathrm{CH}$ patient during an ongoing $\mathrm{H}_{2}^{15} \mathrm{O}$ PET study [31]. The $\mathrm{CH}$ attack-induced activation also increases in the medial thalamus and contralateral perigenual ACC [31].

The exact role of the intracranial blood vessels in the mechanism of cluster headache was investigated by May et al. [31], who performed a $\mathrm{H}_{2}^{15} \mathrm{O}$ PET study in a group of 17 episodic $\mathrm{CH}$ patients ( 9 in the active period and 8 out of their bout) and a MR angiography in a spontaneous $\mathrm{CH}$ and capsaicin-induced pain in 4 healthy volunteers. $\mathrm{H}_{2}^{15} \mathrm{O}$ PET study showed significant activation during spontaneous or nitroglycerine-induced headaches bilaterally in the ACC, ipsilateral posterior thalamus, ipsilateral basal ganglia, ipsilateral inferior posterior hypothalamus, both frontal lobes, bilaterally in the insulae, and in the contralateral inferior frontal cortex. In addition, they found activation in large intracranial vessels on the PET scan which corresponds to a significantly increased blood flow in the internal carotid artery ipsilateral to the headache side, both in $\mathrm{CH}$ patients and in experimentally induced pain [32]. The latter findings further support the neuronal nature of the dysfunction in $\mathrm{CH}$, confirming that intracranial vascular changes are not specific to headache but represent a generic epiphenomenon of the pain.

Sprenger and colleagues [4] measured cerebral glucose metabolism by means of FDG-PET in 11 episodic $\mathrm{CH}$ patients during and outside the bout and compared these 
Table 2 Synoptic table of neuroimaging studies showing three major observations relevant for the pathophysiology of cluster headache

\begin{tabular}{llll}
\hline Method & Posterior hypothalamus activation & Pain neuromatrix involvement & Opiatergic system involvement \\
\hline SPECT & & Di Piero et al. [28] & Sprenger et al. [4] \\
PET & May et al. [30] & Hsieh [29] & Sprenger et al. [6] \\
& Sprenger et al. [31] & May et al. [25] & Sprenger et al. [31] \\
& May et al. [32] & May et al. [32] \\
& Matharu et al. [43] & Sprenger et al. [4] \\
& & Matharu et al. [43] \\
MRI & Lodi et al. [34] & Morelli et al. [39] \\
& Wang et al. [35] & Sprenger et al. [46-48] \\
& Morelli et al. [39] & \\
& May et al. [45] & \\
& Cohen et al. [47] & \\
& Sprenger et al. [46-48] & \\
VBM & Sprenger et al. [46-48] & \\
\hline
\end{tabular}

patients with a group of 11 healthy subjects. With respect to those outside the bout, patients scanned during the bout presented increased metabolism in the perigenual ACC, posterior cingulate cortex, the orbitofrontal cortex including the nucleus accumbens, ventrolateral prefrontal cortex, dorsolateral prefrontal cortex (DLPFC) and temporal cortex, and increased metabolism in cerebellopontine area. Moreover, $\mathrm{CH}$ patients (in and out of the bout) compared to healthy subjects revealed hypometabolism in the perigenual ACC, prefrontal and orbitofrontal cortex [4]. Interestingly, the perigenual ACC was found to be activated in chronic $\mathrm{CH}$ patients, unresponsive to pharmacological therapy, who were treated successfully with occipital nerve stimulation [33].

Further evidence for hypothalamic dysfunction in $\mathrm{CH}$ arises from spectroscopic studies. A study with proton MR spectroscopy ( $\left.{ }^{1} \mathrm{H}-\mathrm{MRS}\right)$ of 26 patients with $\mathrm{CH}$ (18 episodic, 10 in and 8 outside the bout, and 8 chronic) demonstrated that the NAA, a marker of neuronal integrity, is reduced in the hypothalamus of three subgroups when compared to 12 healthy subjects [34]. These data have been confirmed with the same methodology in a group of 47 episodic $\mathrm{CH}$ patients by Wang and colleagues [35], who found in addition, a reduction in the $\mathrm{Cho} / \mathrm{Cr}$ metabolite ratio, both during and out of the bout. This suggests that the hypothalamus in cluster headache might be characterized not only by a neuronal dysfunction but even by changes in the membrane lipids.

With the voxel-based morphometric (VBM) analysis, May and coworkers [36] studied 25 episodic patients with $\mathrm{CH}$ and reported an increase in bilateral hypothalamic gray matter volume, with similar results in patients examined during and outside the bout [36]. Another larger VBM study investigating $75 \mathrm{CH}$ patients (22 episodic inside bout, 35 outside bout and 18 chronic $\mathrm{CH}$ ) was unable to reveal changes in hypothalamic area neither overall nor in subgroups [37].

VBM-MRI findings taken together with those provided by ${ }^{1} \mathrm{HMRS}$ may indicate that the hypothalamus of patients with $\mathrm{CH}$ has an increased neuronal density with reduced NAA, suggesting the presence of either immature or dysfunctional neurons [34, 38]. Moreover, these morphometric and functional changes seem to be a permanent diseaserelated dysfunction since they are not due to the $\mathrm{CH}$ history or the cluster phase [34, 36].

Using PET with the opioidergic ligand [11C]diprenorphine in $7 \mathrm{CH}$ patients (6 episodic and 1 chronic) who are in bout but out of an acute attack, Sprenger and colleagues demonstrated a decreased tracer binding in the pineal gland, but not in any other brain structure commonly claimed to be involved in cluster headache pathophysiology [7, 36]. Furthermore, the authors found an inverse relationship between the duration of cluster headaches and opioid receptor binding in the ipsilateral hypothalamus and bilateral cingulate cortices. The latter observation suggests that descending opioidergic mechanisms in the pineal gland and hypothalamus might be involved in the generation of cluster headache attacks.

The study of Morelli et al. [39] is the only one performing fMRI in order to investigate the pattern of cerebral activation during an attack of $\mathrm{CH}$ in four episodic patients, showing activation of diencephalic regions, mainly the hypothalamus. Additionally, they documented trends of activation in cerebral areas involved in pain processing 
(prefrontal cortex, anterior cingulate cortex, contralateral thalamus, ipsilateral basal ganglia and the insula and the cerebellar hemispheres bilaterally) [39].

\section{Paroxysmal hemicranias}

$\mathrm{PH}$ is a relatively rare syndrome and the clinical features are highly characteristic [40-42]. Patients typically have unilateral, brief, severe attacks of pain, localized over the first division of the trigeminal nerve, associated with cranial autonomic features that recur several times per day. The duration of the pain is between 2 and 30 min with a frequency of between 1 and 40 attacks per day. It is more common in women and in chronic form. $\mathrm{PH}$ responds in a dramatic and absolute fashion to indomethacin, hence the importance of distinguishing it from $\mathrm{CH}$ and SUNCT, which are not responsive to indomethacin. Activation of the hypothalamic gray matter during attacks was also observed in paroxysmal hemicranias. Matharu and coworkers [43] were the first to perform $\mathrm{H}_{2}^{15} \mathrm{O}$ PET in seven patients affected by $\mathrm{PH}$, scanned during acute attackoff indomethacin or pain-free-off indomethacin and painfree due to indomethacin administration. The regions significantly activated during headache-off indomethacin versus the pain-free phase were the contralateral posterior hypothalamus, contralateral ventral midbrain, ipsilateral lentiform nucleus, anterior and posterior cingulate cortices, bilateral insulae, bilateral frontal cortices, contralateral temporal cortex, contralateral postcentral gyrus, precuneus, and contralateral cerebellum [43]. Interestingly, indomethacin administration turned off the persistent activation observed during acute attack-off indomethacin. This study supports the view of paroxysmal hemicrania as a central nervous system disorder and demonstrates for the first time the metabolic correlation with indomethacin efficacy.

Short-lasting unilateral neuralgiform headache attacks with conjunctival injection and tearing

Among the other TACs, SUNCT is a very rare primary headache syndrome, with a male prevalence, characterized by strictly unilateral, severe, neuralgic attacks centered on the ophthalmic trigeminal distribution in association with both conjunctival injection and lacrimation [21, 44]. The duration of each attack is between 5 and $240 \mathrm{~s}$ with a frequency ranging between 3 and 200 per day. Although there are marked differences in the clinical pictures of the trigeminal autonomic syndromes, such as the frequency and duration of attacks and the different approaches to treatment, many of the basic features of SUNCT, such as episodicity, autonomic symptoms, and unilaterality, are shared by other headache types, such as cluster headache and chronic paroxysmal hemicrania suggesting a pathophysiological similarity to these syndromes. By studying 6 consecutive spontaneous attacks of SUNCT with fMRI in a 71-year-old woman, May et al. [45] observed activation during the same scanning session in the ipsilateral inferior posterior hypothalamic gray matter during the attacks, compared with the pain-free state. The same ipsilateral area activation was observed also in a 68-year-old man with an atypical case of TAC resembling SUNCT [46]. Additionally, a clear trend of cingulate cortex, insula, temporal and frontal cortices activation was observed [46]. It has to be noted that activation of the posterior hypothalamus was even bilaterally in the two patients affected by SUNCT in the study by Cohen and colleagues [47] and increases parametrically with increasing levels of pain.

Bilateral posterior hypothalamus activation was also observed in the fMRI study of Sprenger et al. [48] where a 49-year-old male patient was scanned during attacks of SUNCT and pain-free state. Also in this case, multiple activations were observed in brain regions involved in the processing of pain [48].

\section{Conclusions}

The role of imaging in TACs has traditionally been directed at ruling out treatable and reversible etiologies (secondary forms of TAC). However, here we have reviewed several studies which used neuroimaging to better understand the pathophysiology of TACs.

Different brain imaging techniques were employed in order to examine the structure, biochemistry, metabolic state, and functional capacity of the TAC brains. All the abnormalities shown by the imaging techniques can be summarized in three major observations: (1) posterior hypothalamic activation during the attacks; (2) involvement of the pain matrix; and (3) of the central opioid system (Fig. 1).

Hypothalamic hyperactivity ipsilateral to the headache side in $\mathrm{CH}$, contralateral in $\mathrm{PH}$, and bilateral in SUNCT were observed during the attacks in all the PET and fMRI studies, with one exception [4]. This activation has not been reported in between attacks of episodic $\mathrm{CH}$. However, hypothalamic activation is not a specific marker of trigeminal autonomic headaches, since it was observed even during spontaneous migraine attacks without aura [49]. It is noteworthy that the presence of hypothalamic activation in other primary headaches or painful syndromes [50, 51] does not necessarily refute specificity for this brain structure in initiating and maintaining an attack of trigeminal autonomic cephalalgia, particularly cluster headache. In fact, hypothalamic activation not only may reflect a general antinociceptive response in healthy humans and in some 


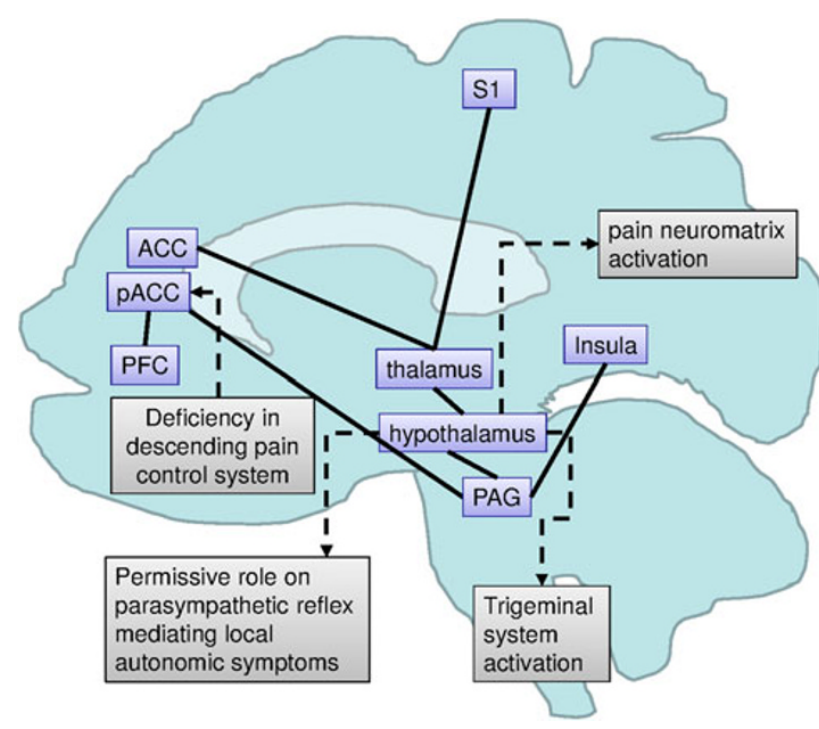

Fig. 1 Schematic brain representation summarizing the findings from the previous studies in cluster headache with the possible pathophysiological consequences. $A C C$ anterior cingulate cortex, $p A C C$ perigenual anterior cingulate cortex, $P A G$ periaqueductal grey area, $P F C$ prefrontal cortex, $S 1$ primary somatosensory area

pathological conditions but may be specifically malfunctioning in cluster headache. As a matter of fact, in patients treated with invasive neurostimulation procedures (occipital nerve stimulation) due to the drug resistance of their chronic cluster headache, the hypothalamic hyperactivation still persists during the stimulator-on condition and despite its clinical efficacy [33]. It has been suggested that persistent hypothalamic activation could be the factor that contributes to generate a central permissive state which predisposes to activation of the trigeminal system, mediating pain, and of the parasympathetic reflex, producing the autonomic symptoms [52]. The latter could also help in explaining why patients still continue to experience autonomic attacks during the neurostimulation-on condition and why pain recurs when it is turned off $[33,54]$.

For the sake of completeness, it has to be acknowledged that there is still a controversy regarding the exact location of this activation since several authors have questioned whether it reflects a real hypothalamic activation or whether this corresponds to the activation of the ventral tegmental area or of other structures anatomically close to the hypothalamus $[55,56]$. The second major finding in trigeminal autonomic headache imaging studies was the involvement of various areas belonging to the so-called pain matrix, such as the prefrontal cortex, anterior cingulate cortex, thalamus, periaqueductal gray, basal ganglia, the insula and the cerebellum. It is noteworthy that these areas are also activated/deactivated in a broad range of painful diseases from visceral to somatic, acute or chronic [51]. For instance, changes in blood flow in the thalamus, insula and anterior cingulate cortex were observed during episodic [57, 58] and chronic [5, 59] migraine attacks, and also in chronic neuropathic [60] and visceral [61] pain. The term pain neuromatrix is used to describe a set of brain regions involved in human nociceptive processing. Moreover, the same brain areas are consistently involved in descending antinociceptive processing. We can thus argue that the metabolic changes in the pain neuromatrix could be considered as the consequence of acute and, more so, chronic pain states like that associated with episodic and chronic cluster headache. This view is reinforced by the fact that the hypermetabolic pattern of most of these brain areas changes, almost restoring normal metabolism, after $\mathrm{CCH}$ patients are successfully treated with neuromodulatory procedures $[33,53]$ or $\mathrm{PH}$ patients undergo efficacious treatment with indomethacin [43].

Several implications derive from the observation of hypometabolism in the perigenual ACC (PACC) of episodic $\mathrm{CH}$ patients scanned outside, and much more during, the bout compared to healthy subjects [4]. Since PACC seems to play a major role in the central descending opiatergic pain control system, its deficiency may be a mechanism that predisposes to the disorder and to its recurrence [4]. The involvement of the opiatergic system in $\mathrm{CH}$ pathophysiology is further confirmed by the same research group who found that opioid receptor availability in the rostral ACC and hypothalamus reduces with the duration of $\mathrm{CH}$ [7] and that low-dosage opioid (levomethadone) induces complete and long-lasting $\mathrm{CH}$ remission [62]. Moreover, in pharmacologically intractable $\mathrm{CCH}$ patients who responded to occipital nerve stimulation, an increased metabolism was observed in PACC in comparison to non-responders [33], further underlining the fact that one of the pathophysiological mechanisms of treatment efficacy in $\mathrm{CH}$ is the restoration of normal opioid analgesia.

In conclusion, to date, the most striking neuroimaging findings in cluster headache are the posterior hypothalamic activation during the attacks, with concomitant pain neuromatrix activation and opioid system involvement as underlined by changes in perigenual ACC.

Given the rapid advances in functional and structural neuroimaging methodologies, it can be expected that these non-invasive techniques will continue to improve our understanding into the nature of the brain dysfunction in cluster headache and other trigeminal autonomic cephalalgias.

\section{Conflict of interest None.}

Open Access This article is distributed under the terms of the Creative Commons Attribution License which permits any use, distribution and reproduction in any medium, provided the original author(s) and source are credited. 


\section{References}

1. May A (2005) Cluster headache: pathogenesis, diagnosis, and management. Lancet 366:843-855

2. Camargo EE (2001) Brain SPECT in neurology and psychiatry. J Nucl Med 42:611-623

3. Accorsi R (2008) Brain single-photon emission CT physics principles. Am J Neuroradiol 29:1247-1256

4. Sprenger T, Ruether KV, Boecker $\mathrm{H}$, Valet M, Berthele A, Pfaffenrath V, Wöller A, Tölle TR (2007) Altered metabolism in frontal brain circuits in cluster headache. Cephalalgia 27:1033-1042

5. Fumal A, Laureys S, Di Clemente L, Boly M, Bohotin V, Vandenheede M, Coppola G, Salmon E, Kupers R, Schoenen J (2006) Orbitofrontal cortex involvement in chronic analgesic-overuse headache evolving from episodic migraine. Brain 129:543-550

6. Sprenger T, Goadsby PJ (2010) What has functional neuroimaging done for primary headache... and for the clinical neurologist? J Clin Neurosci 17:547-553

7. Sprenger T, Willoch F, Miederer M, Schindler F, Valet M, Berthele A, Spilker ME, Förderreuther S, Straube A, Stangier I, Wester HJ, Tölle TR (2006) Opioidergic changes in the pineal gland and hypothalamus in cluster headache: a ligand PET study. Neurology 66:1108-1110

8. Sprenger T, Berthele A, Platzer S, Boecker H, Tölle TR (2005) What to learn from in vivo opioidergic brain imaging? Eur J Pain 9:117-121

9. Lenkinski RE, Schnall MD (1991) MR spectroscopy and the biochemical basis of neurological disease. In: Atlas SW (ed) Magnetic resonance imaging of the brain and spine. Raven, New York, pp 1099-1121

10. Fulham MJ, Bizzi A, Dietz MJ, Shih HH, Raman R, Sobering GS, Frank JA, Dwyer AJ, Alger JR, Di Chiro G (1992) Mapping of brain tumor metabolites with proton MR spectroscopic imaging: clinical relevance. Radiology 185:675-686

11. Soares DP, Law M (2009) Magnetic resonance spectroscopy of the brain: review of metabolites and clinical applications. Clin Radiol 64:12-21

12. Castillo M, Kwock L, Mukherji SK (1996) Clinical applications of proton MR spectroscopy. Am J Neuroradiol 17:1-15

13. Ogawa S, Lee TM, Nayak AS, Glynn P (1990) Oxygenation sensitive contrast in magnetic resonance image of rodent brain at high magnetic fields. Magn Reson Med 14:68-78

14. Fox PT, Raichle ME (1986) Focal physiological uncoupling of cerebral blood flow and oxidative metabolism during somatosensory stimulation in human subjects. Proc Natl Acad Sci USA 83:1140-1144

15. Kim S-G, Ugurbil K (1997) Functional magnetic resonance imaging of the human brain. J Neurosci Methods 74:229-143

16. Kim JH, Shin T, Kim JS, Kim HJ, Chung SH (1996) MR imaging of cerebral activation performed with a gradient-echo technique at $1.5 \mathrm{~T}$ : sources of activation signals. Am J Roentgenol 167:1277-1281

17. Ashburner J, Friston KJ (2000) Voxel-based morphometry-the methods. Neuroimage 11:805-821

18. Whitwell JL (2009) Voxel-based morphometry: an automated technique for assessing structural changes in the brain. J Neurosci 29:9661-9664

19. Ashburner $\mathbf{J}$ (2007) A fast diffeomorphic image registration algorithm. Neuroimage 38:95-113

20. Pereira JB, Ibarretxe-Bilbao N, Marti MJ, Compta Y, Junqué C, Bargallo N, Tolosa E (2011) Assessment of cortical degeneration in patients with Parkinson's disease by voxel-based morphometry, cortical folding, and cortical thickness. Hum Brain Mapp. doi: $10.1002 / \mathrm{hbm} 21378$
21. Matharu M, Goadsby P (2007) Trigeminal autonomic cephalalgias: diagnosis and management. In: Silberstein S, Lipton R, Dodick D (eds) Wolff's headache and other head pain, 8th edn. Oxford University Press, New York, pp 379-430

22. Headache Classification Committee of the International Headache Society (2004) The international classification of headache disorders, 2nd edition. Cephalalgia 24:1-195

23. Norris JW, Hachinski VC, Cooper PW (1976) Cerebral blood flow changes in cluster headache. Acta Neurol Scand 54:371-374

24. Sakai F, Meyer JS, Ishihara N, Naritomi H, Deshmukh VD (1977) Noninvasive 133Xe inhalation measurements of regional cerebral blood flow in migraine and related headaches. Acta Neurol Scand Suppl 64:196-197

25. Henry PY, Vernhiet J, Orgogozo JM, Caille JM (1978) Cerebral blood flow in migraine and cluster headache. Compartmental analysis and reactivity to anaesthetic depression. Res Clin Stud Headache 6:81-88

26. Nelson RF, du Boulay GH, Marshall J, Russell RW, Symon L, Zilkha E (1980) Cerebral blood flow studies in patients with cluster headache. Headache 20:184-189

27. Krabbe AA, Henriksen L, Olesen J (1984) Tomographic determination of cerebral blood flow during attacks of cluster headache. Cephalalgia 4:17-23

28. Di Piero V, Fiacco F, Tombari D, Pantano P (1997) Tonic pain: a SPET study in normal subjects and cluster headache patients. Pain 70:185-191

29. Hsieh JC, Hannerz J, Ingvar M (1996) Right-lateralised central processing for pain of nitroglycerin-induced cluster headache. Pain 67:59-68

30. May A, Bahra A, Büchel C, Frackowiak RSJ, Goadsby PJ (1998) Hypothalamic activation in cluster headache attacks. Lancet 352:275-278

31. Sprenger T, Boecker H, Tolle TR, Bussone G, May A, Leone M (2004) Specific hypothalamic activation during a spontaneous cluster headache attack. Neurology 62:516-517

32. May A, Bahra A, Büchel C, Frackowiak R, Goadsby P (2000) PET and MRA findings in cluster headache and MRA in experimental pain. Neurology 55:1328-1335

33. Magis D, Bruno MA, Fumal A, Gérardy PY, Hustinx R, Laureys S, Schoenen J (2011) Central modulation in cluster headache patients treated with occipital nerve stimulation: an FDG-PET study. BMC Neurol 24:11-25

34. Lodi R, Pierangeli G, Tonon C, Cevoli S, Testa C, Bivona G, Magnifico F, Cortelli P, Montagna P, Barbiroli B (2006) Study of hypothalamic metabolism in cluster headache by proton MR spectroscopy. Neurology 66:1264-1266

35. Wang SJ, Lirng JF, Fuh JL, Chen JJ (2006) Reduction in hypothalamic ${ }^{1} \mathrm{H}$-MRS metabolite ratios in patients with cluster headache. J Neurol Neurosurg Psychiatry 77:622-625

36. May A, Ashburner J, Buchel C, McGonigle DJ, Friston KJ, Frackowiak RS, Goadsby PJ (1999) Correlation between structural and functional changes in brain in an idiopathic headache syndrome. Nat Med 5:836-838

37. Naegel S (2011) Course of disease in cluster headache is reflected by distinct gray matter transformation AAN Abstract

38. Li LM, Cendes F, Bastos AC, Andermann F, Dubeau F, Arnold DL (1998) Neuronal metabolic dysfunction in patients with cortical developmental malformations: a proton magnetic resonance spectroscopic imaging study. Neurology 50:755-759

39. Morelli N, Pesaresi I, Cafforio G, Maluccio MR, Gori S, Di Salle F, Murri L (2009) Functional magnetic resonance imaging in episodic cluster headache. J Headache Pain 10:11-14

40. Antonaci F, Sjaastad O (1998) Chronic paroxysmal hemicrania $(\mathrm{CPH})$ : a review of the clinical manifestations. Headache 29:648-656 
41. Boes CJ, Dodick DW (2002) Refining the clinical spectrum of chronic paroxysmal hemicrania: a review of 74 patients. Headache 42:699-708

42. Cittadini E, Matharu MS, Goadsby P (2008) Paroxysmal hemicrania: a prospective clinical study of thirty-one cases. Brain 131:1142-1155

43. Matharu MS, Cohen AS, Frackowiak RS, Goadsby PJ (2006) Posterior hypothalamic activation in paroxysmal hemicrania. Ann Neurol 59:535-545

44. Cohen AS, Matharu MS, Goadsby PJ (2006) Short-lasting unilateral neuralgiform headache attacks with conjunctival injection and tearing (SUNCT) or cranial autonomic features (SUNA) - a prospective clinical study of SUNCT and SUNA. Brain 129:2746-2760

45. May A, Bahra A, Buchel C, Turner R, Goadsby PJ (1999) Functional magnetic resonance imaging in spontaneous attacks of SUNCT: short-lasting neuralgiform headache with conjunctival injection and tearing. Ann Neurol 46:791-794

46. Sprenger T, Valet M, Hammes M, Erhard P, Berthele A, Conrad B, Tölle TR (2004) Hypothalamic activation in trigeminal autonomic cephalalgia: functional imaging of an atypical case. Cephalalgia 24:753-757

47. Cohen AS, Matharu MS, Kalisch R, Friston K, Goadsby PJ (2004) Functional MRI in SUNCT shows differential hypothalamic activation with increasing pain. Cephalalgia 24:1098-1099

48. Sprenger T, Valet M, Platzer S, Pfaffenrath V, Steude U, Tölle TR (2005) SUNCT: bilateral hypothalamic activation during headache attacks and resolving of symptoms after trigeminal decompression. Pain 113:422-426

49. Denuelle M, Fabre N, Payoux P, Chollet F, Geraud G (2007) Hypothalamic activation in spontaneous migraine attacks. Headache 47:1418-1426

50. Jones AK, Kulkarni B, Derbyshire SW (2003) Pain mechanisms and their disorders. Br Med Bull 65:83-93

51. Tracey I (2005) Nociceptive processing in the human brain. Curr Opin Neurobiol 15:478-487

52. Leone M, Bussone G (2009) Pathophysiology of trigeminal autonomic cephalalgias. Lancet Neurol 8:755-764
53. May A, Lone M, Boecker H, Sprenger T, Juergens T, Bussone G, Tolle TR (2006) Hypothalamic deep brain stimulation in positron emission tomography. J Neurosci 26:3589-3593

54. Leone M, Franzini A, Bussone G (2001) Stereotactic stimulation of posterior hypothalamic gray matter in a patient with intractable cluster headache. N Engl J Med 345:1428-1429

55. Sánchez del Rio M, Alvarez Linera J (2004) Functional neuroimaging of headaches. Lancet Neurol 3:645-651

56. Fontaine D, Lanteri-Minet M, Ouchchane L, Lazorthes Y, Mertens P, Blond S, Geraud G, Fabre N, Navez M, Lucas C, Dubois F, Sol JC, Paquis P, Lemaire JJ (2010) Anatomical location of effective deep brain stimulation electrodes in chronic cluster headache. Brain 133:1214-1223

57. Weiller C, May A, Limmroth V, Jüptner M, Kaube H, v. Schayck R, Coenen HH, Diener HC (1995) Brain stem activation in spontaneous human migraine attacks. Nat Med 1:658-660

58. Bahra A, Matharu MS, Buchel C, Frackowiak RS, Goadsby PJ (2001) Brainstem activation specific to migraine headache. Lancet 31:1016-1017

59. Matharu MS, Bartsch T, Ward N, Frackowiak RS, Weiner R, Goadsby PJ (2004) Central neuromodulation in chronic migraine patients with suboccipital stimulators: a PET study. Brain 127:220-230

60. Iadarola MJ, Max MB, Berman KF, Byas-Smith MG, Coghill RC, Gracely RH, Bennet GJ (1995) Unilateralized decrease in thalamic activity observed in patients with chronic neuropathic pain. Pain 63:55-64

61. Wilder-Smith CH, Schindler D, Lovblad K, Redmond SM, Nirkko A (2004) Brain functional magnetic resonance imaging of rectal pain and activation of endogenous inhibitory mechanisms in irritable bowel syndrome patient subgroups and healthy controls. Gut 53:1595-1601

62. Sprenger T, Seifert CL, Miederer M, Valet M, Tolle TR (2008) Successful prophylactic treatment of chronic cluster headache with low-dose levomethadone. J Neurol 255:1832-1833 